\title{
Interactional Imogen: language, practice and the body
}

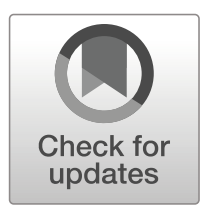

\author{
Harry Collins ${ }^{1}$
}

Published online: 18 June 2020

(C) The Author(s) 2020

\begin{abstract}
Here I try to improve on the available answers to certain long-debated questions and set out some consequences for the answers. Are there limits to the extent to which we can understand the conceptual worlds of other human communities and of non-human creatures? How does this question relate to our ability to engage in other cultures' practices and languages? What is meant by 'the body' and what is meant by 'the brain' and how do different meanings bear on the questions? The central answer developed here is that it is possible, given the right circumstances, for a competent human from any human group to understand the culture of any other human group without engaging in their practices though there are barriers when it comes to communication across species. This answer has important social and political consequences and consequences for the debate about artificial intelligence.
\end{abstract}

Keywords Understanding strange cultures $\cdot$ Language and practice $\cdot$ Language and the body $\cdot$ Hubert Dreyfus $\cdot$ Rachel Dolezal $\cdot$ Artificial intelligence

Are there limits to the extent to which we can understand the conceptual worlds of other human communities and of non-human creatures? Is it necessary to engage in the practice of others to understand their conceptual world? To what extent and under what circumstance can language convey an understanding of the practical world of another

The initial trigger for this paper was the question: 'What does it mean for language to contain practice' put to me at a seminar at the "International Centre for Semiotic Studies "Umberto Eco" in Urbino, Italy, in September/October 2019, though the topic has expanded well beyond this and goes back to a question I have been trying to answer since 1970. Arthur Reber read an early draft and kept me straight on evolution. I benefited greatly from a useful discussion at Cardiff University's Centre for the Study of Knowledge, Expertise and Science (KES) in October, 2019. All remaining mistakes and infelicities are my responsibility. Some of the earlier positions and arguments were published as Collins 1996, 2000 (and Dreyfus's response to this within his, 2000, Festschrift volume), 2004a, 2004b, 2008, 2017a, Collins 2019a; Dreyfus 1967, 1972, 2017; Malpas and Wrathall 2000; Selinger 2003, 2008; Selinger et al. 2007.

Harry Collins

CollinsHM@cf.ac.uk

1 Cardiff University, Glamorgan Building, Cardiff CF10 3WT, UK 
community or group of creatures? What does it mean to say, 'language contains practice'? What is meant by 'the body' and what is meant by 'the brain' and how do different meanings bear on the questions? What are the implications of the answers to the questions for society, for the understanding of society, and for the prospect of artificial intelligence? Those are some of the topics addressed in this paper. I begin by revisiting and reassessing existing positions some of which have been the subject of long running arguments. ${ }^{1}$

\section{Terminological preamble: The meaning of 'practice'}

Words with the root 'practice' are used about 200 times in this paper. Their meaning is usually clear from the context but here I introduce some terminology to distinguish between three meanings for use when ambiguity is still possible. When I say that 'language contains practice' I cannot mean that the sentence 'That was a winning forehand by Federer', actually propelled the ball from Federer's tennis racket in such a way as to prevent his opponent returning it. What I mean is that the sentence is a contributor to the 'practice language' of tennis, which enables fluent speakers of that practice language to understand the physical practice of tennis even if they have never played it. We'll explore this idea at length and return to it in Section 4 of the Appendix. Mostly that usage of the term 'practice' will be set in a context that disambiguates it but I'll provide some special labels for use where there might be doubt. I'll call understanding practice without practising - the usage that occurs in the sentence 'language contains practice', 'practice3'. 'Practice1' is what Feder is doing when he is actually playing of tennis competitively, while 'practice2' was what Federer did a lot of from an early age in order to become one of the best tennis players ever: he practised(2).

I mentioned fluency in language-speaking in the second sentence of this preamble; I can now say that to gain fluency in the practice-language of tennis (that is the language that describes and otherwise 'contains' the practice (practice3), or to gain fluency in any other language, natural or specialist, you need to practice(2) speaking it. That is because language is itself a practicel even though it is not quite such a physical practice(1) as tennis-playing.

Using the new terminology, I can now say that Bert Dreyfus and I used to argue about the possibility of practice 3 : he claiming that you could not understand a practice(3) without being a virtuoso in the associated practice1, whereas I said you must be able to acquire an understanding of practice(3) without practising1 for the world to make sense.

More troubling is how to describe social roles such as being the technical manager of a large scientific project, where decisions on how the practicel of the domain are to be carried forward by others have to be made, thus contributing to the success of the practice1; such a manager does not engage in any physical practicel of the kind he or she is managing, but, crucially, must have practical understanding (practice3) of the

\footnotetext{
${ }^{1}$ To try to keep the explanatory arc of the paper as straightforward as possible, the approach along with the meaning of some terms which may be used in unfamiliar or unclear ways are addressed in more detail in the Appendix. This is divided into 6 sections which will be referred to as the paper unfolds. For example, the meaning of 'practice' as intended here is discussed in Sections 2, 4 and 5 of the Appendix as well as in the 'Terminological preamble'.
} 
domain. Is such a manager engaged in his or her own kind of practicel as well as practice3? The same kind of question applies to sports coaches, influential literary critics, and so on. Luckily, there is no need to resolve this terminological problem in order to understand the arguments presented here. ${ }^{2}$ It is tempting to invent the term 'practicela' to cover such a case but I prefer not to diffuse the philosophical tension over where practice starts and ends.

\section{Part I: The existing position and the debate}

In a paper entitled, 'Interactional Expertise as a Third Kind of Knowledge', published in this journal in 2004, I argued that fluency in language has usually been taken to be a matter of explicit knowledge but actually it also gives rise to tacit understandings, including that of the practices $(1+3)$ associated with the language; the term used to describe a conceptual grasp of another's world that included an understanding of their practices without necessarily having practised or having the ability to practice their practices $(1+2)$, was 'interactional expertise'. 3

In a paper called 'Language and Practice', published in 2011, I argued that the role of practical skills in understanding practices has been over-emphasised and I distinguish between interactional expertise and 'special' interactional expertise. Special interactional expertise involves acquiring fluency in the language and an understanding of practices but without actually practising anything or necessarily having the ability to practice anything relevant. On the other hand, 'contributory experts', who do practice at least a subset of the language-domain's practical skills, are also 'ordinary' interactional experts since they too have to understand other practices that pertain to their form of life but that they don't actually practice. In various places I argue that we could not understand how human societies work and we could not understand how we could have an efficient division of specialist labour, and that includes the specialty of technical management, without the notion of interactional expertise. ${ }^{4}$ The running of societies and the organisation of the division of labour depend on understanding others' practices without being one of those others or engaging in their distinctive or specialist practical skills. The claim is made that interactional expertise is possible because 'language contains practice'.

\subsection{Understanding is not translation}

In setting out to explore the extent to which we can understand other cultures, it is important to note that understanding a language is not the same as fluently translating it. This allows that it is possible to understand two or more languages which include mutually incommensurable concepts. Translation from one language to another is a

\footnotetext{
${ }^{2}$ The problem is also described in Collins and Evans 2015, using the terminology of contributory and interactional expertise: when does interactional expertise become contributory expertise?

${ }^{3}$ The most complete existing analysis of the origins of the concept of interactional experts, and its still unresolved problems as a concept, is Collins and Evans 2015, which also contains a comprehensive reference list.

${ }^{4}$ See Collins and Sanders 2007, for a description of interactional expertise from the viewpoint of the project manager of LIGO and, subsequently, the 30-m telescope.
} 
different problem. It is probable that those best placed adequately to translate language ' $A$ ' into language ' $B$ ' will be fluent in both $A$ and $B$ but this does not mean that translation is possible because there may be things that can be said in language $A$ and not said exactly in language $B$ and vice versa. The second thing to clarify is that though it is stated in the previous paragraph that acquiring interactional expertise does not involve 'actually practising anything or necessarily having the ability to practice anything relevant' this does not apply to the use of the language itself. Becoming fluent in a language $i$ s acquiring a practice - the practice of speaking fluently. Children do not learn their native language by translating it into a language they already know, they learn without self-consciously knowing how they learn, just as they learn to walk. We never consider that learning a physical practice is equivalent to translating it into another physical practice which is already known and acquiring fluency in a language is the same. ${ }^{5}$ In both cases, the acquisition of the skill of speaking or of walking, happens only after enough 'practice2'. In the case of language-learning, whether by children or adults learning a second language, fluency is best achieved, or only achieved, by immersion among native speakers of the language. ${ }^{6}$

\subsection{Interactional expertise and the body}

One consequence of the claim that practice(3) can be understood without practising $(1+$ 2 ) is that it should be possible for individuals to acquire interactional expertise even if they do not possess a body of the kind necessary to engage in the relevant physical practices - the body need only be adequate to engage in the spoken discourse. This claim bears on, among other things, the well-known philosophical position of the late Hubert Dreyfus, as expressed in an influential paper published in 1967 entitled 'Why Computers Must Have Bodies in Order to Be Intelligent' and followed up by a very well-known book published in 1972 entitled What computers can't do, which had a second edition. ${ }^{7}$ Dreyfus disagreed with the idea that it is possible to understand practice without practising, and this disagreement gave rise to a long-running episodic debate with the author, starting in the early 1990s and continuing until 2017, when, sadly, Bert Dreyfus died. ${ }^{8}$

\subsection{The division of labor and practice languages}

The paper published in 2011 mentioned above contained the following figure - Fig. 1 which a number of analysts seem to have found handy for representing the way the division of labour bears on the relationship between language and practice. ${ }^{9}$

\footnotetext{
${ }^{5}$ Which is not to say that there are not certain transferrable skills such as the kind of balance needed for roller skates or roller blades, which could benefit the acquisition of ice-skating or skiing skills.

${ }^{6}$ This is not to say that teaching second languages may not begin with some translation and explicit learning of vocabulary and grammatical rules.

${ }^{7}$ Dreyfus 1972 and see the second edition entitled What computers still can't do, published in 1992.

${ }^{8}$ The major positions were published but the debate also continued in friendly personal meetings at conferences. The continual interaction with Dreyfus's view was important to me in developing the position I set out here, as explained in Collins 2019a.

${ }^{9}$ I refer to various remarks at conferences
} 


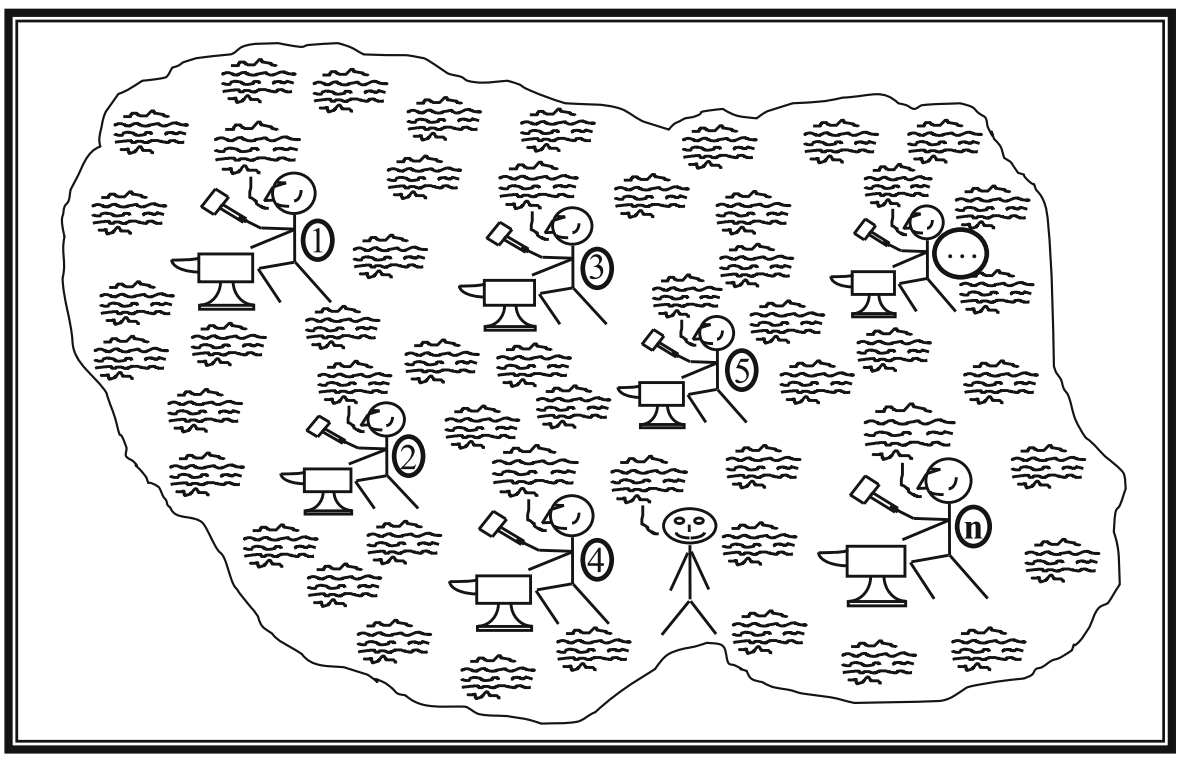

Fig. 1 A practice domain (originally, Collins 2011, Fig. 2)

The figure shows the division of labour in a specialist domain with a number of subspecialists - numbered 1-n - within it. Gravitational-wave detection physics - 'GW physics' - was the example discussed but this is not important: it could be any specialist domain, big or small. ${ }^{10}$ The hammers and anvils represent the exercise of different specialist practical expertises within GW physics while the bundles of waves represent the common 'practice language' - the medium of the interactional expertise - which makes a productive division of labour possible. That is, the possession of (normal) interactional expertise in GW physics makes it possible for, say, specialist 2 to coordinate his or her work with specialist 4 even though 2 cannot do 4's practical work; the same applies across the domain. The smiling figure without a hammer and anvil is a special interactional expert who has acquired fluency in the language but cannot practice $(1+2)$ any of the specialist practices. One can see that the only difference between the smiling figure and the numbered specialists is the possession of, perhaps, a single practical expertise! The difference cannot lie in the ability to practice $(1+2)$ 'the practices found in the domain' since there is no universal 'domain practice' (outside of fluency in the domain practice language_: the specialists practice(1) only one specialty each (or maybe a couple). This makes it easier to understand how someone who does not practice $(1+2)$ at all can come to understand the full range of domain practices because that is what the contributory experts, $1-n$, have to accomplish if they are to

\footnotetext{
${ }^{10}$ I pick on gravitational wave physics because I was engaged with the field from 1972 to the first discovery of a gravitational wave in 2015, and beyond, writing four books and many papers on the topic. Many of the concepts developed here grew out of watching the way physicists worked and developed their knowledge and from my acquisition of enough of their understandings to pass as a gravitational wave physicist in Imitation Games (Giles 2006; Collins 2017b Ch 14). Sections 1 and 2 of the Appendix deal with why science is a suitable topic for the analysis of the relationship between language and practice and why the insights gained from studying science can be generalised to practices in general. Imitation Games are discussed below, and also in Section 3 of the Appendix.
} 
coordinate their work with one another, and that is why the contributory experts must also be interactional experts.

The other thing that the figure helps to bring out is that the specialist 'practice language' found in the domain - the language acquired by the smiling figure and represented by the bundles of waves - would not exist in the absence of the specialists $1-n$ actively carrying out their practices. The practice language could not be developed by a collection of smiling figures doing nothing other than conversing because there must be practices(1) going on if there is to be a 'practice language' in the first place; if there were no such practices taking place there would be no practice(3) for the language to 'contain'. The domain's practices(1), as engaged in by the contributory experts, 1-n, are corralled and captured in the domain practice language and can then be used to transmit an understanding of those domain practices to those like the smiling figure, and to the contributory experts in respect of the majority of the practices(1) that they do not practice(1) themselves. The language is a property of the group which inhabits the domain, not any individual: the language absorbs and is formed from, among other things, all the practical understandings of the practicing individuals, 1-n, and it then makes an understanding of all those practices(3) available to every individual who is fluent in the domain language including those, like the smiling figure, who do not practice $(1+2)$ at all. This is the first thing that is meant by 'language contains practice'.

The second things that is meant is that the level of practice(3) contained in the language is sufficient to enable the fluent to make practical judgements that are as good as those made by contributory experts. This is how it is that technical managers (ideally fluent and accomplished versions of the smiling figure), can run specialist projects without engaging in any of the physical practices pertaining to the domain. ${ }^{11}$ The level of practical understanding that can be acquired from the language alone is, however, insufficient to enable the interactional expert to be engage competently in any of the relevant practical skills - you cannot learn to ride a bike, or do any of the physical skills pertaining to GW physics, by talking about it, you have to practice bike-riding or physics respectively (though, as we have seen, there is a complication when it comes to how to talk about the practical (is that ' 1 ' or ' 3 '?), skills of management, peer review, coaching, and so forth, which themselves make contributions to the domain with consequences for the effectiveness of the outcome of all the more obviously physical practices.

The third meaning of 'language contains practice' refers to one of the ways in which interactional expertise is acquired, namely that much practical understanding can be implicitly gleaned from the un-explicated relationship of words and silences in the linguistic corpus pertaining to a practical domain - the practice language. ${ }^{12}$

\subsection{Different bodies}

If, as argued above, it does not require a body of the type needed to engage in a relevant practice(1) to acquire interactional expertise, it seems to follow that entities with

\footnotetext{
${ }^{11}$ This is discussed at length in Collins and Sanders 2007. Gary Sanders was the project manager of LIGO and later became the project manager of the $30-\mathrm{m}$ telescope, which is the post he held when the 2007 paper was written. See Section 5 of the Appendix for further discussion of what is meant by 'the same' practical judgements and how these relate to subjective experiences.

${ }^{12}$ I don't claim that this exhausts the meanings of 'language contains practice'.
} 


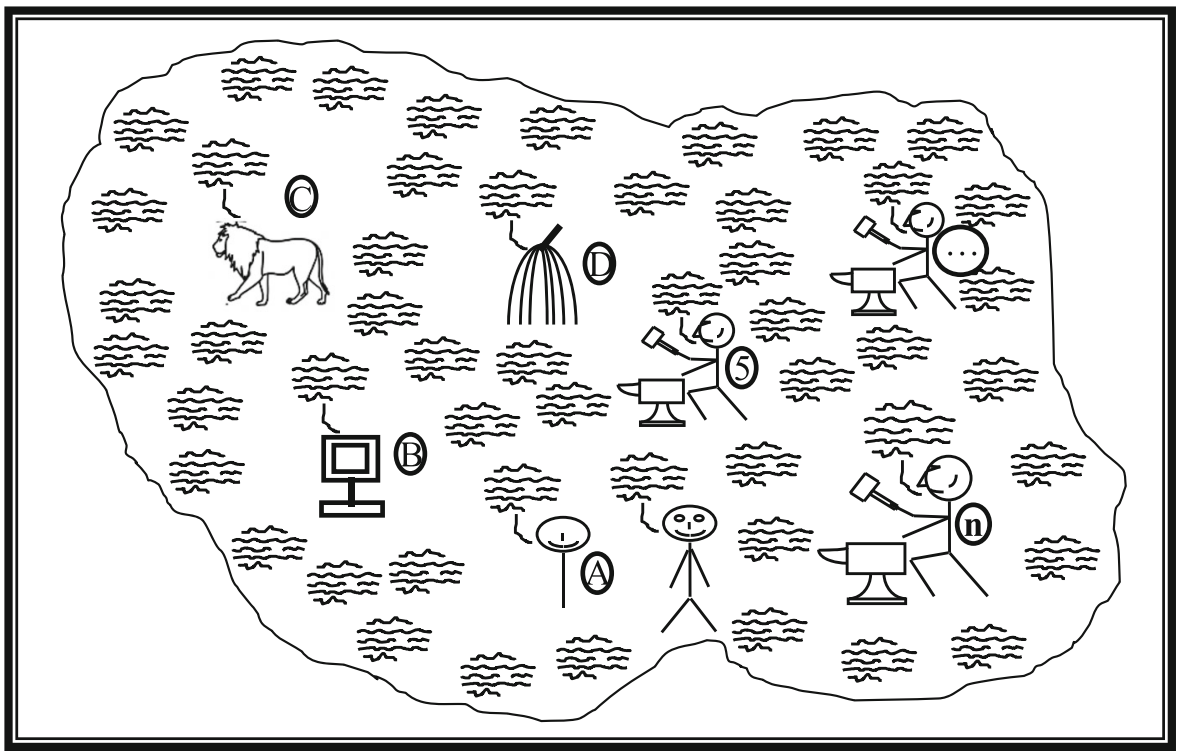

Fig. 2 What other kinds of entity might be able to acquire interactional expertise?

various kinds of bodies could acquire interactional expertise through assiduous immersion in the spoken discourse. They would, of course, need to be able to speak because immersion in language is central to the argument. In Fig. 2, the representations of contributory experts 1, 2, 3 and 4 have been replaced by figures with various kinds of bodies who/which represent four other candidates for the possession of interactional expertise in some typically human practical domain such as gravitational wave physics: these are a severely physically challenged person (A); a computer (B); a lion (C); and an alien heptapod (D). The possibilities associated with first three of these have been discussed in the existing literature while the heptapod discussion is new to this paper. Obviously, we are drifting between situations that have been experienced and thought experiments which illuminate possibilities that have not been experienced or might be experienced in the future. We will also mention our relationship to cats, dogs and chimpanzees as the argument develops and this will bring some additional relevant experience to bear on our relationship to the imagined heptapods.

The computer and physically-challenged person were discussed in connection with Dreyfus's claim that computers must have bodies to be intelligent. The discussion arose out of Doug Lenat's counter-claim that a severely, congenitally, physically-challenged person, 'Madeleine', described by Oliver Sacks in his 1985 book, was nevertheless fully fluent in language as a result of her extended conversations with her carers. ${ }^{13}$ Lenat argued that, therefore, a computer without a human-like body could also be fully fluent and, if we take passing the Turing Test as an indicator of intelligence, such a

\footnotetext{
${ }^{13}$ Madeleine was blind and wheelchair-bound from birth, and unable to perform simple tasks such as wiping her own bottom. The actual competence of the body in question is not philosophically germane, however. Should Madeleine have been fully fit but never used her eyes and limbs, the same would apply. In respect of gravitational wave physics, I describe myself as, effectively, not having a body because I don't practice it.
} 
computer could be intelligent. In the published debate I sided with Lenat on this matter but I now find I have to modify my position to some extent as will be explained below.

In the case of the lion, both Dreyfus and I drew on Wittgenstein's well-known claim that 'if a lion could speak we would not understand what it said'. Dreyfus argued that this was because the lion, having a body so different to that of a human, and living in such a different world of activity, would not share human concepts and humans would not share the conceptual world of the lion. For example, lions did not have backward bending knees so would not share the concept of 'chair' with humans. I claimed that, following the idea that the conceptual structure of a language is a property of the collectivity, not the individuals, the problem was not a matter of any individual lion's body, or any individual human's body, but the bodily shape and associated language of lions and humans in general:

[Not] every entity that can recognise a chair has to be able to sit on one. That confuses the capabilities of an individual with the form of life of the social group in which that individual is embedded. Entities that can recognise chairs have only to share the form of life of those who can sit down. We would not understand what a talking lion said to us, not because it had a lion-like body, but because the large majority of its friends and acquaintances had lion-like bodies and lion-like interests. In principle, if one could find a lion cub that had the potential to have conversations, one could bring it up in human society to speak about chairs as we do in spite of its funny legs. It would learn to recognise chairs as it learned to speak our language.

In the same way, I argued that a human baby brought up among lions could learn to speak 'lionese' even though its body was not such as could enable it to practice lionlike practices. I now find I have to reconsider these positions too.

\subsection{Learning 'cloud'}

Now, to begin to move into new territory, imagine a 'smiling figure' embedding him or herself among heptapods with a view to learning heptapod language - which we'll call 'Cloud' (Fig. 3). Heptapods are imaginary inhabitants of a distant solar system. I choose heptapods since such creatures were portrayed as visitors to Earth in the film Arrival; they are the right kind of alien for our purposes and will be already familiar to some readers. ${ }^{14}$ Fig. 3 is like Fig. 1 but with heptapods substituted for gravitational wave physicists and Cloud substituted for GW practice language. Cloud could be a specialist domain language (related to, say, 'thargitational force control' $-\{$ TFC $\}-$ which is in curly brackets to indicate that there is no exact translation into any Earth language). ${ }^{15}$

\footnotetext{
${ }^{14}$ It was the introduction of the imaginary heptapods that caused me to rethink existing positions, but in retrospect, the same logic follows from thinking hard about cats and dogs. The trouble is that much contemporary thought about cats and dogs and other animals stresses their continuity with humans; the heptapods are not subject to this tendency.

${ }^{15}$ The terms 'tharg', 'thargitational', 'thargitronic', etc. are meant to indicate some kind of alien science belonging to a conceptual world we do not share.
} 


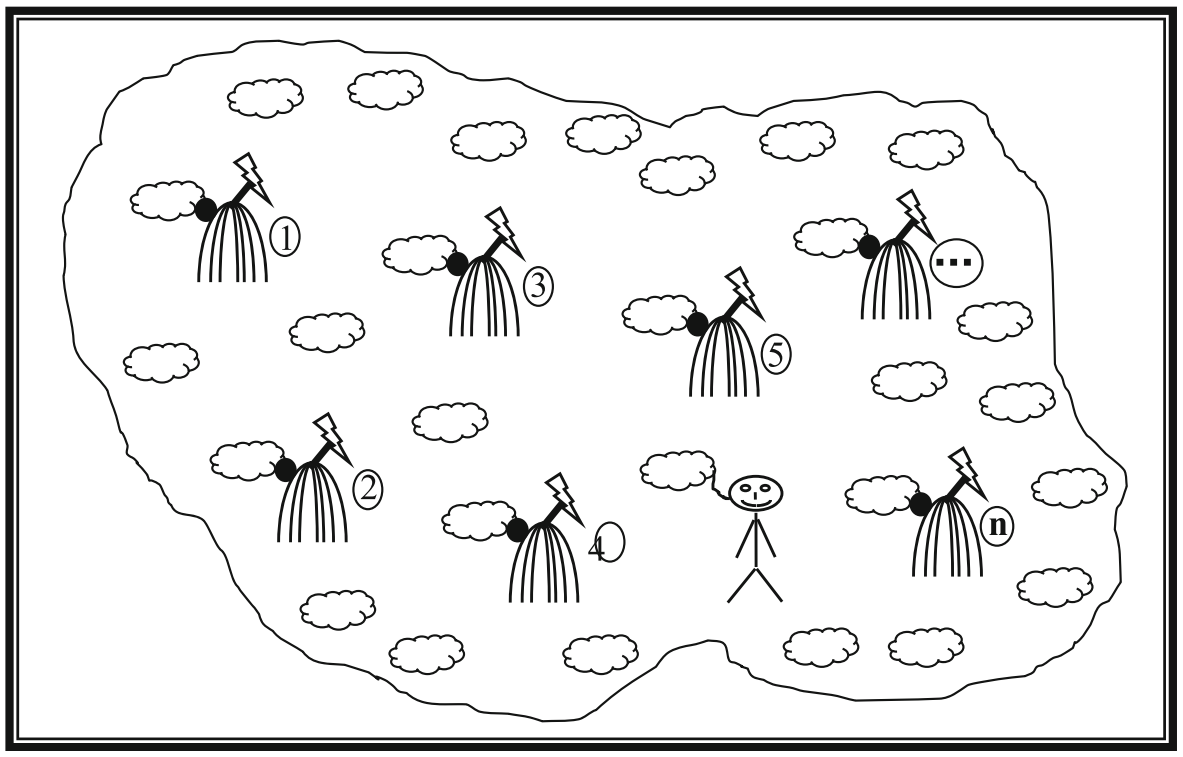

Fig. 3 The smiling figure acquires the language of heptapods?

One difference between the situations represented in Figs. 1 and 3 is that in the first case the smiling figure comes ready-equipped with the ubiquitous language of human society, into which the specialist domain language is embedded, whereas the smiling figure in Fig. 3 has to acquire the ubiquitous language of heptapods as well as the specialist practice language of $\{\mathrm{TFC}\}$. This difference is like the difference between sociologists and ethnographers, on the one hand, who study groups within their own societies, and anthropologists, on the other, who study remote, isolated, societies and have to learn the native language, as well as the details of the culture from scratch. The difference means that anthropologists have to spend a number of full years with the distant groups they want to understand (to avail themselves of sufficient opportunities to practice 2 the native language), whereas sociologists and ethnographers, working with groups within their own society, find they need to spend only a few months per year. ${ }^{16}$ But this difference is one of degree of difficulty not principle. The problem of learning, say, gravitational wave physics by immersion is, difficulty aside, a perfectly good example of the process of linguistic socialisation; there is no need to travel to different lands or search for radical differences in the conceptual world to study it. ${ }^{17}$

\footnotetext{
$\overline{{ }^{16} \text { Some reports of this difference }}$ will be found in Collins et al. (under submission).

${ }^{17}$ The same seems to apply to the Whorfian hypothesis, which is manifested just as well by, say, the changes in understanding and perception associated with acquiring fluency in the language of GW physics as it is by, say, the differences in colour perception of different remote societies with different colour terms (assuming there are no evolutionary or epigenetic changes associated with language differences). This insight probably originated with Kuhn's (1962) notion of incommensurable scientific paradigms though it was anticipated by Winch. (And see Section 1 and 2 of the Appendix.)
} 


\section{Part II: Revisions and refinements}

There are, however, more significant differences between Figs. 1 and 3 than those that have been discussed so far; these are indicated by the way the heptapods have been drawn for the purposes of the thought experiment. First, their organs of speech and hearing are different to ours and that could be fatal because we will never acquire fluency in Cloud unless we can speak it. Their speech and hearing organs are represented by the black disk on their right shoulders/hips from which Cloud emerges. Not having the equivalent, the smiling figure, on first encountering the heptapods, could not even begin to acquire their language. But there are different ways of imaging this problem: if, say, Cloud were to differ from human language simply by using frequencies outside the range of human speech and hearing, the problem could be solved. We would need something a bit more complicated than the little bent lines we have been using to link the mouth of the smiling figure and other human figures to their utterances; we would need something that does the job of the heptapods' black disk. But if the significant feature of heptapod language is merely something like mismatched frequency, we could fit the human with a prosthesis that converts frequencies. We already fit humans with prostheses to make speech and hearing possible where some physical deficiency makes it otherwise impossible (think of Steven Hawking). In the same way, if the heptapod is to fit into Fig. 1, it too will need a prosthesis to replace the little bent line that has been drawn. There is, then, no necessary conceptual difficulty but we will find (below) that things become significantly more interesting when we make the difference between the two mediums of communication more profound.

There are definitely significant differences to be explored when we get to the body shape and practices of the heptapods as they are represented in Fig. 3. While, in Fig. 1, specialist engagement with GW physics was represented by arms wielding hammers and striking anvils, engagement with $\{\mathrm{TFC}\}$ is represented by a stubby appendage and a lightning-like shape intended to indicate that the heptapods' world is much more different to ours than even that of the most distant human societies. The 'big' question is whether it would ever be possible for the smiling figure to understand such a world however long they were immersed in their society and language.

This question is easily answered so long as it is believed that scientific culture is universal and that even creatures from alien solar systems could do nothing other than discover the same scientific facts as we on Earth have discovered, thus providing a basis of conceptual commonality so that understanding would be possible through brilliant enough translation, but we are assuming here that science is a matter of different cultures supporting incommensurable paradigms. ${ }^{18}$ The interactional expertise hypothesis intimates that the problem of incommensurability in the absence of translation can be surmounted by immersion because acquiring another paradigm/language is not the same as translating one paradigm/language into another. ${ }^{19}$ But we are still left

\footnotetext{
${ }^{18}$ Note the assumption in the first part of this sentence informs the plaques sent into space in 1972 and 1973 with the Pioneer 10 and 11 spacecraft and showing figures readily recognisable to those sharing our scientific understandings.

${ }^{19}$ The film Arrival does well at portraying the problem of incommensurability but shows it to be resolvable by logic-like translation techniques supplemented by some kind of disappointingly 'magical' direct communication transmitted through hand contact.
} 
with the question of whether the heptapod world could be so different (that the incommensurability gap would be so great), that we would never be able to grasp it however long we were immersed in the language. It could be that we would fail because of the sheer capacity of the heptapod brain compared to ours and/or radical differences in the structure of the brains needed to support such different bodies. $^{20}$

\subsection{Language production and brains}

It is a little easier to see how differences in brain capacity and structure might prevent the acquisition of interactional expertise by returning to the language difference and imagining it to be more profound. Suppose the heptapods communicate \{thargitronically\}, whatever that means. We just don't have the brain structure to detect and decode \{thargitronic\} transmissions. Our brains are different because, in part, the way they have evolved is connected to the way we speak.

Most terrestrial non-human animals do not have the vocal apparatus to produce enough modulations to have led their brains to develop under evolutionary pressure in a way that enhances the ability to control those modulations. At the same time, the apparatus of speech in most such animals did not evolve to take advantage of those brain developments in a positive feedback cycle. The associated brain developments were almost certainly evolutionarily entwined with the development of bipedality, opposable thumbs, the discovery of fire and the nutritional value of cooked food, and, of course, a rich social life, but elaborately modulated speech was almost certainly in there too. The enhanced cognitive capacity of a brain that does develop in this way is going to be useful for far more than just speech but the point is that the way a species speaks cannot be isolated from the rest of its evolutionary development.

\subsection{Lions, computers and Heptapods}

Now let us return to lions. Wittgenstein framed the problem by imagining a talking lion. But the fact of the matter is that we do not have any such lions. Now, it could be that this is simply because no lion cub has ever been brought up with humans but the evidence of other animals' interactions with humans strongly indicates that there is more to it than this. Thus, Chimpanzees have been brought up with humans with the intention of teaching them to speak or, at least, communicate using signs, but such success as there has been is very limited. Furthermore, there is a continuing natural experiment of this type going on with domestic cats and dogs, many of which are immersed in social circumstances that match the upbringing of human babies yet which manifestly fail to lead to any grasp of human language and human culture (note their sexual, toilet, and hunting behaviour and their lack of appreciation of the significance of nakedness). What little in the way of mutual understanding that has been achieved by chimpanzees and dogs and some other animals tends to be taken as an indication that there is continuity between these species and humans but the question we are dealing with here is the ability to acquire fluency in human culture and the answer to

\footnotetext{
${ }^{20}$ The argument in this paper is unaffected by thinking of the brain as more extensive than what is in the head and, in important respects, extending through the body - at least through the skein of nerves and perhaps further; it is convenient, however, to refer to 'the brain' rather than 'the brain and its extensions'.
} 
that question is clear: no cat, dog, or chimpanzee has ever come anywhere close to passing a Turing Test or imitation game nor can we imagine it happening. ${ }^{21}$ These failings are not to do with absence of the conditions for socialisation, which are excellent in the case of these creatures, but with the capacity and/or structure of their brains; humans departed from most of the animal world in terms of their communicating, cooperating and understanding abilities, and in the associated development of their brains in the course of evolution. The relationship of the brains of lions, chimpanzees, cats and dogs and human brains is similar to that which we can imagine existing between human brains and those of heptapods.

As we have argued, languages, whether ubiquitous or specialist, develop by absorbing all the talk associated with the range of practices associated with many individuals while an individual who can do none of the practices, perhaps because their body is unsuitable, can still acquire an understanding of the practices from the language. Cats, dogs, chimpanzees, and so on, cannot do this. It is clear from the case of animals that, irrespective of the bodily shape of the species or individual, it must still have a brain that is not too different to the brains possessed by the members of the collectivity who developed the language in the first place if it is to acquire fluency in the language. Change the nature of the brain in significant ways and the language becomes inaccessible however deep the immersion.

So, the ability to learn the language is, after all, deeply related to the body but, under this argument, it is not in the way that Dreyfus and others have claimed. It is not related to the body, or the physical experience, of any individual but to the bodies and experiences of the species whose brains have evolved in a certain way corresponding to the evolutionary advantage of the bodies typical of the species. While my claim that a talking lion could learn to understand us, and we could learn to understand talking lions if immersed among them for long enough, was a useful way of illustrating the meaning of interactional expertise, it was fanciful in that the reason there can be no talking lions has to do with the way their brains have evolved and this does have to do with their collective bodily form. It is true that if we had talking lions we could learn their language and they ours, but the reason we don't have talking lions is because of the nature of their bodies - which did not give rise to right kind of evolutionary trajectory to allow their brains and speaking apparatus to develop human-like capacity and/or structure.

In the same way, Lenat's riposte to Dreyfus's claim that computers must have bodies to be intelligent - namely that Madeleine was intelligent while, in at least one sense, she did not have a body - was also over-simple, and my, unqualified, positive response to it, was over-hasty: Madeleine had a brain that could absorb human language only because the bodies of her co-humans had given rise to brains and speaking apparatus that had evolved in the right way and Madeleine, having a body that was genetically aligned with the species, however untypical her individual version of it, had also acquired a brain belonging to the species. Computers do not start with that advantage and that means Lenat's claim is not so decisive after all! One can see the problem still more clearly by imagining a neo-Lenat arguing that, given that the case of Madeleine shows that bodies are not important in the acquisition of intelligence/language, there is

\footnotetext{
${ }^{21}$ That there is a large component of selective breeding rather than natural evolution in the case of dogs only makes their lack of speaking ability more striking.
} 
nothing to stop a lion, a cat, a dog or a chimpanzee, becoming as fluent as us if brought up among us. And we simply know that is not true - it is not true because the body-type of the species is not such as to have given rise to a brain of the right type. The same applies to computers - they do not have a species body of the type that gives rise to the right kind of species brain. It could still be that the only way to build a brain as effective as Madeleine's is to have it develop in a body that has evolved in a way that will support it, and computers do not have Madeleine's advantages in this respect. That's not Dreyfus's argument but it is an argument for the need for a species body.

Dreyfus opened himself up to Lenat's argument because he would not make the distinction between the contribution to understanding of bodies at the collective level and the contribution of individual bodies. Thus Dreyfus painted himself into the corner of having to claim that no sports coach could be any good at their job unless they had practiced the sport at the highest level and that there must be something strange about GW physics if I could pass as a GW physicist without having practised GW physics. $^{22}$ Dreyfus would not take seriously the idea of interactional expertise and would not accept that without it there were severe difficulties in the way of understanding various obvious features of social life such as the efficient division of technical labour. Dreyfus would have been on far more secure ground and could more immediately have countered Lenat if he had invoked the body in a collective, species-level, way.

\subsection{The generalised body}

Thinking in terms of the need for the right kind of species brain makes it more reasonable to claim that if AI pioneers could build a machine that mimics the human brain even though it does not share the evolutionary heritage of humans, it would have the potential to be socialised into any human society, purely by sufficient immersion in its linguistic discourse, and thereby pass any Turing Test however demanding. If the building of such a brain could be accomplished there would be no need for it to have a body that could engage in the practices of that society so long as it could be fully immersed in the spoken discourse of that society. Whether this can actually be done without developing it within a species body is what the science of AI is, effectively, trying to find out.

So now we return to the argument of Dreyfus and his colleagues. Would a computer need something else in addition to a species brain: might it still need a generalised body equipped with the various senses shared by humans and animals? The argument is that it would need many sense organs, a sense of up and down, a sense of front and back, a sense of movement, a sense of the downward pull of gravity, a sense of bonding with others, and so on. We have already discussed 'the individual body' and 'the species body'. It is the species body that gives rise to both ubiquitous and specialist languages and to the kind of evolved brain that can learn them. If the arguments are correct, we understand how an individual belonging to a language-speaking species can have a quite untypical body yet still become fluent in the language, acquire interactional expertise, and understand typical or specialist practices that pertain to the species body. I argue that Dreyfus was confusing the individual body with the species body; I still think this. But in defending the need for a body if an entity is to be intelligent, another

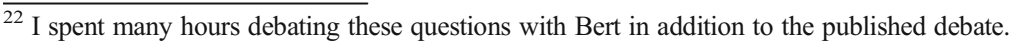


meaning of body arose in the course of the debate: the generalized body. Madeleine has all of the senses of a generalized body whereas a computer with no robotic elements, does not. If it is claimed that the kind of body needed to be intelligent is a generalized body it would follow that Lenat is incorrect in stating that Madeleines' actual or effectively missing bodily components renders a computer that is without a body just as capable of being intelligent as she is: Madeleine and the computer are not equally disembodied because Madeleine does have a generalized body as well as a species body. $^{23}$

I understand that the perceived importance of the generalized body was bolstered for Dreyfus by the work of Samuel Todes (2001). ${ }^{24}$ The trouble is that, computers aside, all the entities discussed in this paper - humans, whether physically challenged or not, or whether skilled practitioners or not, lions, dogs, cats, chimpanzees, and, putatively, heptapods - are all identical in terms of possession of a generalized body, so the notion is no use for arguing philosophically about the limits of their potential intelligence, or their ability to understand incommensurable cultures though immersion: the only thing the generalized body bears on is the possibility of non-robotic computer-intelligence. Furthermore, if it is the generalized body that is crucial then it becomes harder to explain why Dreyfus would insist you had to play sport before you could be an effective coach since non-players have generalized bodies as much as players. It might certainly be advantageous for a sports coach to have played the sport for the kinds of reason presented in Table 2 (below), which describes certain advantageous circumstances for acquiring interactional expertise, but these are matters of social contingency rather than philosophical principle. The generalized body, to reiterate, has no bearing on the concept of interactional expertise where it is a matter of sharing language among creatures with similar evolved brains. Lenat's argument from Madeleine does support the idea of interactional expertise among humans, however, and it does not look as though we can understand the social world without interactional expertise irrespective of the notion of generalized bodies. But, so far, it remains, that on the face of it, computers do not have generalized bodies and it may be that they need them. ${ }^{25}$

Existing arguments found in the literature for the need for generalized bodies remain unsatisfactory, however, because, as a result of the not separating out groups and individuals, they have been mixed up with arguments about the need for individual bodies to have practiced specific skills if their embedded brains are to understand those skills. $^{26}$ That the argument for the need for a generalized body for any kind of humanintelligence on the one hand, and the argument for the need for a body capable of executing particular practices for understanding such practices, on the other, are

\footnotetext{
$\overline{{ }^{23}}$ This is my summary of one of the arguments found in Selinger et al. 2007 and championed by Selinger.

${ }^{24}$ I posit this influence in Collins 2017a. Bert Dreyfus (2017) has an article in the same volume which discusses Todes 2002 book. My obituary, entitled 'Remembering Bert Dreyfus', and which also speculates about the role of Todes (2001) in Bert's thinking, is Collins 2019a.

${ }^{25}$ Another argument that arose in the debate, championed by Selinger more than Dreyfus, was that once one had a body one could 'extrapolate' from one kind of activity to another. But this argument would not support the specialist coach thesis because of its generality: under extrapolation there would be no specialists since one practice could stand in for all practices. Furthermore, being able to practice anything would, by extrapolation, enable one to understand any practice. The argument from extrapolation does not work in the absence of an argument about its limits.

${ }^{26}$ I refer to the literature that emerged out of the debate between Dreyfus, Selinger and myself and referenced throughout this piece.
} 
unrelated is even more clear in that it seems the first can still be defended while the second cannot. Because of the existing confusion, the minimum requirements for a generalized body have not been presented by those who want to defend the idea and have taken part in the debate referenced above. Thus, from this debate we cannot learn at what point, as we strip components and senses away, a body would cease, according to the argument, to be enough of a generalized body to support human-like intelligence.

Given the separation between language and practice and the confusion of the arguments, the onus still seems to lie on showing that at least a generalized body is necessary for understanding human culture. Even if such a body can be shown to play a vital part in the intelligence of humans as we know them, this does not show its necessity for efforts to mimic human-type intelligence with computers. Perhaps a computer could be equipped with sensors that would detect up and down, the force of gravity, and so on, which would simulate the physics of human senses, but those who support the idea of the need for a generalised body might not accept that equipping a computer with 'sensors' could ever amount to equipping it with 'senses'. For example, some could argue that some degree of movement is vital, some might argue that consciousness would be vital, others might argue that a living substrate is vital. All we can do here is clarify the questions and restate the position taken here that practising(1) is not a requirement of understanding practice where there is fluency in the language, even if some minimal, but undefined, generalised body is necessary for acquiring fluency in the first place, but the need for a generalised body, and its limits, needs to be established with much more care.

\subsection{Brain structure}

Returning to our imagined heptapods, we may not be able to understand them because of differences in brain capacity/structure but the problem might also apply in reverse. They might not be able to understand us, with our hammers, anvils, and paucity of limbs, however long they were immersed in our language, not because of the capacity problem but because of the brain-structure problem. In the same way, even though our brains are more powerful than those of cats, dogs, lions and chimpanzees, the structure problem almost certainly prevents us understanding them. For example, we probably cannot comprehend a world in which, say, smells, play such a dominant role in perception.

\subsection{How empirical evidence bears on the matter of cultural comprehension}

\section{A) Necessary conditions for acquiring interactional expertise}

The problem we are exploring is a conceptual one: is it possible for any human to acquire fluency in the language of any unfamiliar human culture and what happens when we get to non-humans? But the problem again needs to be separated into two parts: individual and collective. The conceptual problem can be made clearer by asking it in reverse: is it impossible for $a$ human under any circumstances to grasp certain human cultures because of their conceptual distance from them and the incommensurability of the cultural concepts? This is quite different to the question of whether it is possible for a particular human to grasp another culture in a particular set of 
circumstances. The answer to the particular human questions is 'no': there are all kinds of deficiencies in humans and all kinds of negative circumstances that prevent a strange culture being grasped. ${ }^{27}$ It is important to distinguish between the individual and the general problem because otherwise the difficulties that attend the grasping of another culture by particular humans under particular circumstances can be taken to provide an answer to the general problem: the token is mistakenly taken to represent the type.

Table 1 sets out the individual capabilities and the conditions necessary for acquiring the interactional expertise of another culture. The necessary abilities and conditions are found only in cell 15, the intersection of row 4 and column 6 . Columns two to five show why it is that individual entities might not be able to acquire a culture with columns three to five referring to humans. By 'wrongly developed brain' is meant something like the brain of a feral child who has not learned language by the necessary age. In columns three to five there will be no acquisition of interactional expertise because the embedded person has insufficient interactive ability. ${ }^{28}$

\subsection{The means for immersion in language}

Rows two and three deal with issues that have not so far been discussed. The second row indicates the situation where there is no spoken language pertaining to the practices of a domain - no 'practice language'. If there is no practice language, then one cannot acquire interactional expertise. ${ }^{29}$ One possible case is the experience of war on the frontline. Soldiers say that no-one who has experienced war at the front line would ever go to war again, yet wars continue. But with interactional expertise in mind, it should be possible to understand the full horror of war without actually experiencing it so long as you immerse yourself in the talk of those who have experienced it - therefore there should be larger numbers of young persons who know war, and would refuse to go to war again, because they understand its horrors without having directly experienced it. ${ }^{30}$ On the other hand, there may be no opportunities to acquire good interactional expertise in the practice of war on the front line because the discourse does not exist? Soldiers seem reluctant to talk about ghastly experiences to those who have not experienced them themselves. On the contrary, much of the language of war is jingoistic, a kind of fake discourse intended to mislead the young sufficiently for them to volunteer. Simple absence of relevant discourse in a society is an absolute barrier to the acquisition of interactional expertise. $^{31}$

The third row refers to situations where the discourse exists but it is impossible for an outsider to access it. This is a standard topic in sociology and anthropology. Some

\footnotetext{
${ }^{27}$ For example, this author has experienced the lack of capacity to understand the world of the theory of amorphous semi-conductors in spite of his attempt to acquire it through immersing himself in the discourse. A brief account of this particular failure can be found in Collins $2019 \mathrm{~b}$

28 The notion of 'interactive ability' is found in the second row of the 'Periodic Table of Expertises', which is first published in Collins and Evans, 2007, p 14, but has been much reproduced. Columns 3 and 4 are related to the Z-axis and column 5 to the Y-axis of the 'Three Dimensions of Expertise' - see Fig. 2 in Collins, 2013 (p257), published in this journal.

${ }^{29}$ The problem is first discussed with a number of examples in Collins 2012.

${ }^{30}$ Section 5 of the Appendix discusses the relationship of experience to 'understanding' a little more fully.

${ }^{31}$ That interactional expertise involves understanding of practices suggests a new way of thinking about what is going on in various kinds of propaganda, holocaust denial, jingoism, and so on - it is about trying, through spoken discourse, to create inauthentic practical understandings of features of the world.
} 
Table 1 Necessary conditions for acquisition of interactional expertise

\begin{tabular}{|c|c|c|c|c|c|}
\hline \multirow[t]{3}{*}{$\begin{array}{l}\text { CRUCIAL } \\
\text { RESOURCES }\end{array}$} & \multicolumn{5}{|c|}{ BRAIN } \\
\hline & $\begin{array}{l}\text { WRONG } \\
\text { SPECIES }\end{array}$ & but not e & $\begin{array}{l}\text { RIGHT SPEC } \\
\text { ough interac }\end{array}$ & $\begin{array}{l}\text { IES } \\
\text { ive ability (IA) }\end{array}$ & $\begin{array}{l}\text { SPECIES } \\
+ \text { enough }\end{array}$ \\
\hline & 2 & $\begin{array}{c}3 \\
\text { Damaged } \\
\text { or weak } \\
\text { brain }\end{array}$ & $\begin{array}{c}4 \\
\text { Wrongly } \\
\text { developed } \\
\text { Brain }\end{array}$ & $\begin{array}{c}5 \\
\text { Insufficient } \\
\text { perseverance }\end{array}$ & 6 \\
\hline $\begin{array}{l}2 \text { No practice } \\
\text { language }\end{array}$ & 1 & 4 & 7 & 10 & 13 \\
\hline $\begin{array}{l}3 \text { No access } \\
\text { to language }\end{array}$ & 2 & 5 & 8 & 11 & 14 \\
\hline $\begin{array}{l}4 \text { Language + } \\
\text { access }\end{array}$ & 3 & 6 & 9 & 12 & 15 \\
\hline
\end{tabular}

groups, such as certain cults, the very rich and powerful, or criminal gangs, are not prepared to allow outsiders to spend time immersed in their cultural worlds - they have nothing to gain and everything to lose. Du Bois's (1994) double-consciousness theory illustrates the logistics of immersion and the way it relates to power, though in that case it worked in the opposite way, since the immersed have something to offer to the powerful: black persons had to know the worlds of both themselves and their white masters and mistresses if they were to fulfil their role as servants in a satisfactory way and were invited, and even paid, to spend their working lives immersed in that world; white persons had no need to understand the world of blacks.

B) Advantageous conditions for acquiring interactional expertise

Access to the domain language is a necessary condition of acquiring interactional expertise but, as the large literature on gaining access to communities indicates, there are many contingencies that arise in social life that make immersion harder or easier. Some of the latter are set out in Table 2 (above).

\subsection{Confounding variables}

The number of confounding variables that attend attempts to acquire interactional expertise as represented in Tables 1 and 2 and the contingent way in which they arise in everyday life make it difficult to investigate its acquisition in natural settings. As intimated, it is easy to confuse the in-principle possibility of the acquisition of interactional expertise and the contingent features of its acquisition; great care is needed to disentangle them. For instance, many actual cases of the acquisition of interactional expertise will involve some involvement in certain of the associated practices and some 
Table 2 Advantageous conditions for acquisition of interactional expertise

\begin{tabular}{|c|c|c|c|}
\hline \multicolumn{4}{|c|}{ ADVANTAGEOUS RESOURCES } \\
\hline \multicolumn{2}{|c|}{ Access to language } & \multicolumn{2}{|c|}{ Perseverance } \\
\hline $\begin{array}{c}\text { Visual proximity to } \\
\text { practices }\end{array}$ & $\begin{array}{l}\text { Participation in } \\
\text { practices }\end{array}$ & Lots of time & Lots of money \\
\hline
\end{tabular}

observation of the circumstances and material apparatus associated with them because immersion in the language may require this kind of proximity or even involvement. It could be a condition of access to the target group that the acquirer spend time at the workplace where most of the conversations take place and this will involve seeing and, and perhaps even practising $(1+2)$, to a limited extent, that which is being talked about. And it is almost certainly the case that seeing practice(1) taking place, and some degree of actual practicing, will make the acquisition quicker and easier for various reasons. But this does not make this kind of proximity or practice a necessary condition as the key cases of the physically disadvantaged discussed above makes clear. That is why lack of this kind of proximity and engagement in a degree of practice do not feature in Table 1 as conditions for the acquisition of interactional expertise.

\section{Part III: Consequences for social life and the argument about computers}

\subsection{The universal comprehensibility of all human cultures by humans}

The other side of this analysis has important consequences both philosophically and for our understanding of everyday life. What we have done is explore some of the limits to understanding other ways of being in the world and we have located them in biological differences in the brain related to biological differences in the body. But, while the argument is, admittedly, negative, and it is hard to prove a negative, we have no reason to think that there are any such deep biological differences among groups of humans. If this is true, we have answered the question posed in the first sentence of the paper. Since all groups of humans are biologically the same in respect of the acquisition of language any human who has sufficient individual ability, can, in principle, acquire fluency in any human language/culture. To repeat, all groups of humans can speak human-like languages and this suggests that the default position is that all groups of humans have brains that are similar enough to allow them to gain fluency in each other's languages. And, given the idea of interactional expertise, it follows that they would be able to understand each other's practices and cultures even though they did not practice them. Lenat's argument is sound to the extent that it shows that any sufficiently capable human could pass a demanding Turing Test however bodily challenged so long as they could engage in spoken discourse. For it not to be true, given what has been argued here, human brain type would have had to diverge as human cultures diverged. At worst, what has been argued shifts the onus onto those 
who want to disprove the argument and intimates that they might find themselves arguing that cultural differences among humans are based in biological differences something that few analysts who emphasise the importance of culture would be ready to accept.

'The brains of all groups of humans are biologically the same.' What does this mean in the context of this argument? As indicated, in Table 1, it does not mean that there is not variation of ability among individual brains nor variation among the circumstances that engender understanding of an initially unfamiliar culture that are encountered by individuals. Individual brains differ at birth depending on genetic legacy and the environment of the individual womb and they continue to diverge in terms of the number and distribution of connections after birth depending on social and environmental factors. There is also evidence that there are detectable changes in brain structure related to activity as an adult and it is at least possible that since at least some of what we think of as 'brain processes' take place in the skein of nerves or even more remote regions of the body, this wider conception of 'the brain' is going to be directly and individually affected by changing body shape. ${ }^{32}$ Thus we know that language learning may be impossible if certain brain developments have not been effected as a result of learning a language by a certain age and that fluency in second language learning may be impossible to achieve after a certain age and that will include the possibility of acquiring fluent interactional expertise in certain esoteric domains after a certain age. These limitations are not, however, passed on through the normal processes of evolution. What 'all the brains of all human groups are biologically the same' does mean is that there are humans in every human group that could acquire the fluency of any other human group given the right conditions as represented in Table $1 .{ }^{33}$

The very plausible and, so far, unfalsified, conjecture is, to repeat, that humans can potentially acquire an understanding of any human culture through long enough immersion in the spoken discourse of that culture while the same does not apply across species - humans, lions, dogs, cats, chimpanzees, and 'heptapods'. To express this another way: all humans have evolved a similar 'species brain' irrespective of the individual body. This species brain is capable of supporting an indefinitely large number of types of what we can call 'cultural brain'. The cultural brain is that which has acquired one culture or another, some of which might well have a relationship of incommensurability with one another. What is being argued is that humans with any kind of cultural brain can potentially if not actually acquire any other kind of cultural brain.

\subsection{Social and political consequences}

If it is correct, as has been argued, that a person from any human group can, in principle, acquire the language and culture of any other human group, then there are significant social and political consequences: it makes the world 'epistemologically

\footnotetext{
${ }^{32}$ For example, there is evidence that taxi-drivers' brains continue to develop distinctive structural features in adult life. https:/www.ncbi.nlm.nih.gov/pmc/articles/PMC18253/.

${ }^{33}$ It could be argued that there could be some biology-based inheritance through epigenetic processes, but we will not take this possibility into account.
} 
safe' for anyone who claims to understand a human culture or practice that is not their own. It does not make this easy for such a person - it does not make it 'logistically safe' or 'politically safe', only epistemologically safe. Therefore, it is possible in principle for there to be sports coaches and commentators who are not top participants, or even any kind of participant, in the relevant sports ${ }^{34}$; it makes it possible to be a responsible journalist; an authentic novelist, actor, or film-maker; it makes it possible for a few persons to develop enough technical understanding to become authentic technological activists; and it makes the world epistemologically safe for participatory sociologists, anthropologists, and ethnographers; it makes it safe for criminologists to claim to understand crime without committing crime.

This claim also has deep political consequences: it means that humans can, as far as epistemological principle is concerned, authentically represent a group that they have not been born into. And it means you do not need the same type of sexual organs or the same skin colour of those whose cultural world you want to understand. In principle, men can fully understand women and women can fully understand men, blacks can fully understand whites and whites can fully understand blacks, and so on. It makes the world epistemologically safe, then, for someone like a Rachel Dolezal.

Rachel Dolezal, is a white woman who pretended to be black and became president of the 'National Association for the Advancement of Colored People' (NAACP) chapter in Spokane, Washington, for a year or so around 2014/15 until her deceit was uncovered and she confessed to the subterfuge. She claimed that in spite of being white she self-identified as black. ${ }^{35}$ There are various complications surrounding the Dolezal case, such as surround the details of her birth, and the fact that she acted deceitfully, but here we want to discuss the epistemological principle only. Accordingly, we'll invent an idealised Dolezal who, following the naming-precedent of Jackson's 1982, 'Monochrome Mary' discussion, we'll call 'Interactional Imogen'. Imogen could be an honest white person who declares that she self-identifies as black, mixes with the black community, and becomes a political representative for the black community. Our argument is that Imogen has committed no 'epistemological misdemeanour': if she fulfilled the conditions explained in Table 1, including spending enough time immersed in black culture, perhaps, but not necessarily, aided by the conditions set out in Table 2, she could be capable of representing black culture with epistemological authenticity and effectiveness equal to that of a person who was born black. $^{36}$

We can, of course, replace black and white in the Interactional Imogen story with any kind of physical or cultural difference so long as all the actors are equipped with human-like brains: Madeleine is an Interactional Imogen - a physically challenged person representing the physically unchallenged; Collins is an Interactional Imogen, a non GW-physicist representing GW physicists in Imitation Games; and non-participatory sports coaches are Interactional Imogens taking on the role of representing the participants in the sports they coach; and so on.

\footnotetext{
34 This point is made still more clear in Section 5 of the Appendix

35 https:/en.wikipedia.org/wiki/Rachel_Dolezal.

${ }^{36}$ But see Section 6 of the Appendix. Note that the argument also makes the world epistemologically safe for Du Bois's double consciousness thesis, which takes it that blacks can take on the consciousness of whites.
} 


\section{Part IV: Summary and conclusion}

We have re-examined the relationship between culture, language and the body with the aim of clarifying the issues. Along the way we have found that we need to think in terms of three kinds of brain: species brain; cultural brain and individual brain. We also need to thing about three kinds of body: generalized body; species body; and individual body ${ }^{37}$ Brains can be classified into types of species brain, the human version of which supports a set of cultural brains, though abilities are limited by the individual brain. A body defined by its possession of typical senses is a generalized body; generalized bodies can be classified into types of species body made up of individual bodies with different set of capabilities.

The fulcrum of the argument is that there is no reason to think that one kind of species brain can acquire the cultural brain of another species but that, on the other hand, every human brain can, potentially, depending on the capabilities of the individual brain and circumstances, acquire any other human cultural brain by immersion in its spoken discourse. To understand the argument requires that the difference between the 'philosophical' constraints on the acquisition of cultures and the constraints that emerge from differences in individual capabilities and differences in circumstances not be confounded. It they are separated it shows that the form and capability of the individual body is not intrinsic to the acquisition of a culture so long as the species body and brain are appropriate. The reason is that the practices pertaining to a culture can be 'understood' without practicing them. Since the only current way we have of acquiring a species brain is by growing it in a species body, the ability to acquire human-like cultures currently depends on having a human-like body though it need have only minimal practical capacities.

It remains an open question whether an artificial human-type species brain could be constructed based on computer technology. What this would imply is building an artificial brain which would have the capacity to acquire human cultures in the same way as humans can acquire them - through embedding in the linguistic discourse of human cultures. (Deep learning is one direction of research which has shown a lot of promise but is not there yet.) The entire argument is summarized in Table 3 in which, interestingly, the individual body has no place:

If it is true, as the bottom left-hand cell indicates, that any human species brain, irrespective of the capacity of its generalized body, can potentially acquire any human cultural brain, then certain things follow about human societies. Given the right circumstances and competences, what we have called an 'Interactional Imogen' could acquire the culture of any group of humans, to the point of being able to authentically represent them, however much their bodily form diverged from hers. This affects the way we understand many professions and roles in social life.

\footnotetext{
$\overline{37}$ In another place I will suggest there is a fourth type of body that may be one of the crucial obstacles for the development of AI, thus supporting Dreyfus once more about the need for bodies but, once more, with a different kind of argument. The fourth type of body is one that can give rise to trust; as it is there seems no way of making non-living 'intelligent' entities worthy of trust yet trust is the key to the development of knowledge (Collins et al. under submission).
} 
Table 3 The argument summarised

\begin{tabular}{|c|c|c|c|}
\hline \multicolumn{2}{|c|}{ HUMAN SPECIES BODY } & NON-HUMAN BODY & COMPUTER \\
\hline \multicolumn{3}{|c|}{ Has generalised body } & No body \\
\hline \multicolumn{2}{|c|}{$\begin{array}{l}\text { Has human species brain } \\
\text { irrespective of form of } \\
\text { individual body }\end{array}$} & \multirow{3}{*}{ Has non-human brain } & \multirow{3}{*}{ Has artificial brain } \\
\hline \multicolumn{2}{|c|}{$\begin{array}{c}\text { Individual brain + } \\
\text { Individual circumstances }\end{array}$} & & \\
\hline Appropriate & Inappropriate & & \\
\hline \multicolumn{4}{|c|}{ CAN ANY CULTURAL BRAIN BE ACQUIRED? } \\
\hline & & NO & $\begin{array}{l}\text { DON'T KNOW } \\
\text { YET (but will } \\
\text { need to be } \\
\text { socialisable) }\end{array}$ \\
\hline
\end{tabular}

\section{Appendix}

\section{Section 1: Origins of the question and approach}

The origins of this argument are found in the early 1970s with the start of 'the sociology of scientific knowledge' (SSK). The later philosophy of Wittgenstein (eg his 1953) is often cited as the most important source for this movement. It is often said that the new approach to science was 'naturalistic' - thus the slogan could well have been Husserl's 'zu den sachen', and phenomenology, and its offspring, ethnomethodology, were heavily implicated in the early days of SSK. And, of course, there is a literature claiming that Wittgenstein's move from his earlier to his later philosophy was motivated by phenomenology (see, eg Munson 1962 - which was one of this author's early sources - along with the works of Alfred Schutz - and see Gier 1981.) ${ }^{38}$ 'Den sachen', in this case, were not physical things but the nature of science. Again, following Husserl's warning that true grasp of phenomena can easily fall 'victim to the seduction of language', SSK rejected the formulaic and selfjustificatory accounts of their world by philosophers of science and by scientists themselves. The object was to find a way to reflect truly upon the 'form of life' of science.

The Wittgensteinian concept of form of life turns on the integral nature of concepts and practices. For this author, an influential gloss was that of Peter Winch's 1958 book in which he asks the reader to consider the discovery of the germ theory of disease: the concept of germ makes sense only together with the activities associated with hygiene;

\footnotetext{
${ }^{38}$ Claims like this are always disputable but in the case of SSK, the sheer excitement and urgency of the project soon took over from justification in terms of origins; of course, this itself could be said to be in the spirit of Husserl's slogan.
} 
for surgeons to continue to operate in dirty bloodied waistcoats would nullify the concept of germ while the seemingly ritualistic pre-operative scrubbing would make no sense without the concept of germ. The concept of interactional expertise does depart a little from these early ideas because while concepts and actions are two sides of the same coin at the societal level, this does not quite apply to an individual embedded within the society. For instance, to grasp the concept of germ an individual does not have to be a surgeon themselves nor do any scrubbing themselves, they have only to be immersed in the language of a society where these things are taken for granted. (Reflect upon your own understanding of the concept of germ!) This, note, is not a formulaic use of language; it is not a matter of explaining things; it is not a matter of grasping propositions. It is the regular, mostly unreflective, use of language to maintain the taken-for-granted form of life. And to use language in that way requires a form of fluency that embeds the practical life of the society in which it is spoken; that is one of things explored further in the main part of the paper.

\section{Section 2: Science as practice}

Among the things discovered by the new approach to science pioneered in the 1960s and early 1970s was that what was taken by scientists and others to be a straightforward 'cognitive-intellectual undertaking' turned on unarticulated skilful physical and conceptual practices. For example, this author's study, of the way scientists learned to build a new kind of laser (The TEA-laser), published in 1974 and still very much in circulation, revealed it to be like acquiring a new language in that no-one succeeded in acquiring the 'fluency' to make the laser work unless they spent time in the social company of those who had already built a successful device. This was the case even though the scientists could and did avail themselves of the most detailed published descriptions and instructions. Scientific disputes turned out to be battles about which new language, in the broadest sense - which new form of life (or 'paradigm') - should become the scientific vernacular.

\section{Section 3: Development of artificial intelligence and the Imitation Game}

Another change since the days of the foundation of the phenomenological movement, one reflected in the second part of the title of this journal, is the development of the field of artificial intelligence; we now have an experimental means of exploring knowledge of sufficient power to influence our understanding of what human knowledge is. For example, we now know that the most difficult parts of human knowledge to reproduce artificially, are not the esoteric but the ubiquitous parts, including fluency in natural language itself. Alan Turing's prescient idea of the Turing Test is more and more relevant and even the brilliant recent successes of deep learning still fail in the face of simple tests of vernacular understanding. ${ }^{39}$ A Turing-type test, with humans rather than computers,

\footnotetext{
${ }^{39}$ See, for example, Collins 2018, especially Chapter 10 for a series of examples. One standard example going back to Terry Winograd's $1975 \mathrm{PhD}$ thesis is the 'Winograd schema'. Thus the pronoun in the translation from English into a gendered language like French differs according the which word of the two offered at the end of this sentence is chosen to complete it: 'The trophy would not fit the suitcase because it was too big/ small. To choose the right pronoun requires an understanding of the conventional practicalities of trophies and suitcases; that this is still beyond computers becomes clear in a demandingly-designed Turing Test or Imitation Game.
} 
can provide a practical definition of what it means to understand practice - what 'practice3' means (and it is far more than it is imagine to be by those who like to dismiss it as merely 'talking the talk') A person can be said to understand if they can pass an 'Imitation Game' and the claim is that sufficient interactional expertise will enable a person to pass an Imitation Game designed to detect understanding of the practical world without actually having to practice within that world. ${ }^{40}$ To look at matters from the other side, to insist on a definition of understanding practice which rests on having practiced $(1+2)$, leads to absurd consequences - such as Dreyfus flirted with in his claims about sports commentators and coaches being incapable of doing their jobs unless they had played the sport at the highest level. Given that every person's practical experience as they pass through life is unique, obsession with the idea of physical practice being necessary for understanding that practice, projects us into a world of isolated individuals, none of whom understand each other. What, then, would human language be for?

\section{Section 4: Distinction between understanding practice and being able to practice}

Understanding practice in the sense used here, is not sufficient to be a skilled practitioner: to learn to ride a bike or play the violin needs practice - in the conventional sense of doing things over and over again until the skill is perfected (practice2)-not just talk about practice. But to understand that practice, according to the idea of interactional expertise, one need only spend enough time immersed in the conversation of bike-riders and violinists. But to repeat a point already briefly made in the main body of the paper, this leads to one of the yet unresolved philosophical problems of the idea of interactional expertise (usually discussed under the heading of interactional versus 'contributory expertise'). ${ }^{41}$ The problem is that being a successful coach or a successful manager of a large scientific project means making practical contributions to the person or team being coached or managed without engaging in their physical practices. And the ability to do this successfully increases with practice and experience of the managerial kind! So, should these abilities, which in at least some cases are a matter of interactional expertise, be described as practices(1) or not? One way to move forward might be to separate the two kinds of contribution as having to do with somatic tacit knowledge on the one hand - that is 'muscle memory' and the like, associated with the affordances of human bodies - and other kinds of tacit knowledge less obviously so tied. ${ }^{42}$ Fortunately, nothing of practical importance seems to depend on resolving this problem but it does invite further philosophical analysis.

\section{Section 5: Distinction between understanding practice and bodily experiences}

What is meant when we say that an interactional expert could make 'the same practical judgements' as one who had practices, is that in an Imitation Game, if the judge were to

\footnotetext{
40 'Imitation Game' is capitalised when it refers not to the parlour game that was the inspiration for Turing's test but the carefully developed experimental version developed by the author and his team at Cardiff University and including the more detailed work done from 2011 to 2016 supported by European Research Council Advanced Grant (269,463 IMGAME) €2,260,083 'A new method for cross-cultural and crosstemporal comparison of societies'.

${ }^{41}$ See Collins et al. 2016, for a discussion of what it means to make a contribution to a scientific field.

${ }^{42}$ For the distinction between three kinds of tacit knowledge, see Collins's 2010, book, Tacit and Explicit Knowledge.
} 
ask questions designed to expose someone who was pretending to be one who practised (it could be a top level specialist within the field of gravitational wave physics, or a virtuoso violinist or ballet dancer), the judge would fail to spot the difference between the answers of the pretender and the genuine virtuoso however hard they made the questions, so long as the pretender had met the conditions of acquiring top level interactional expertise (see Table 1 and surrounding discussion). Questions about how exercising a certain practice is experienced could well be included and could still be answered by one who has sufficient interactional expertise but no practical experience themselves; this, of course, is a demanding level of interactional expertise and, as Table 1 sets out, may be unattainable in certain cases for logistical reasons.

This leaves the question of whether understanding practice via interactional expertise leads to the ability to imaginatively experience the experiences of one who has actually engaged in the practices (to simplify things we'll talk only of palpably physical practices here). I am inclined to say that this is implausible in the case of certain bodily experiences such as giving birth, suffering torture, or the ecstasy of sexual desire and love even though writers can sometimes appear to engender such experiences in readers. ${ }^{43}$

The question that follows is whether you can really 'understand' these bodily experiences if you have not experienced them even if you can pass the relevant Imitation Games. A constructive critic of a draft of this paper asked what was meant by 'immersion' in a culture, adding, that for a Dolezal-like Imogen, it would surely require being a victim of racism and structural oppression. The contrast offered was that the so-called 'understanding' could only be 'simply a grasp of a set of propositions'. But that is why the paper published in this journal in 2004 and referred to in the first line of the main paper, is entitled 'Interactional Expertise as a Third Kind of Knowledge'; it is to make the point that interactional expertise stands between 'qualia' on the one hand, and a grasp of a set of propositions on the other: that those two possibilities do not exhaust the world. The tendency to think that they do exhaust the world seems to arise because it is taken that all that can be articulated is, by that fact, sets of propositions, whereas the argument in 2004, and continued here, is that language is far richer than sets of propositions. Hence the deliberately provocative claim, 'language contains practice' and the elaboration of some of the unconscious ways this happens when language is understood as creating and maintaining a form of life. There is also the rather more obvious point that fluent language speaking itself is a practice(1) - learned like other practices by practising(2) - that is how you become fluent in a language - not by studying vocabulary and grammar but by practising among already fluent speakers.

One direction this question about subjective experience leads is the huge, and in my view, not very illuminating, debate about the role of consciousness in human understanding. In part this is driven forward by the argument about the role of consciousness in artificial intelligence. Once more, I incline to sidestep this question by defining what is meant by understanding in a practical way that does not depend on elucidating internal states. This practical way is the Imitation Game/Turing Test and I can report that we have done investigations that indicate, if not prove, that actual physical

\footnotetext{
$\overline{43}$ This author can attest to being unable to continue reading a multi-volume history of the Second World War when he reached the account of how Polish resisters were treated by the Nazis; can attest that, after an initial foray, he chose not to pursue research in the field of forensic science as he sensed the potential for personal damage following from accounts of certain murders; and can attest to the experience of the beginnings of such damage on reading certain testimonies from the concentration camps and deciding he could not read more.
} 
experience is not crucial to passing the test. Thus our tests strongly indicate that it is very hard indeed for a sighted 'judge' to identify a person who has been blind from their early years pretending to be sighted; in the experiment the judge is directed to ask questions that relate to experiences the blind person would not have encountered in the short period of life before they lost their sight and compare the answers to those of a fully sighted person. An example of such a question might be, 'Roughly how far across the line does a tennis ball have to be to be clear to the umpire that it is 'out'? The contrast with sighted persons pretending to be blind when questioned by blind persons is stark. We explain this contrast as due to the fact that most blind persons are immersed in the discourse of sighted persons throughout their lives whereas sighted person are not generally immersed in the discourse of blind persons. The same kind of argument (we have not done the experiments), applies to other major congenital differences (eg caused by Thalidomide) between the bodies of individual humans and the bodily shape of the collective that gave rise to the native language. It is not apparent that persons with bodies that depart from the norm are obviously deficient in their conceptual grasp of the world as evidenced in their use of language or ability to make relevant judgements.

I say that none of this is proved by our experiments or by the arguments, but the point is to move the locus of the argument from the all too easy assumption that only full experience can lead to understanding to the initially counter-commonsensical (in certain philosophical circles), claim that language alone contains practice enough to engender understanding in a strong sense.

\section{Section 6: Identity politics}

The point made about Dolezal is a very narrow one: if the idea of interactional expertise is correct, she cannot be faulted on epistemological grounds: she cannot be faulted on the grounds that in principle she could not have had the right kind of knowledge to represent a group to which she did not belong because she had not shared the full lived experiences of that group. The maintenance of this view rests on the position set out in Section 5 of this appendix.

These are some claims that are not made in this paper:

i. Dolezal was not morally at fault for deceiving others

ii. Dolezal had in fact acquired the necessary level of interactional expertise to do what she claimed to be able to do

iii. The resources to acquire sufficient interactional expertise to accomplish what Dolezal had claimed to accomplish are available in society (though it is likely that they are and remember that Du Bois's thesis rests on this kind of possibility).

iv. It is politically efficacious to be represented by those with interactional expertise rather than practical experience of prejudice and the like

But note that if too much weight is put on authenticity of experience then society will change. For example, at the time of the early civil rights movement, the white activists who drove into the Southern States to make their protests and were murdered would have to be seen as making every kind of 
mistake; the legal system should be partitioned according to group identity. And so on.

Open Access This article is licensed under a Creative Commons Attribution 4.0 International License, which permits use, sharing, adaptation, distribution and reproduction in any medium or format, as long as you give appropriate credit to the original author(s) and the source, provide a link to the Creative Commons licence, and indicate if changes were made. The images or other third party material in this article are included in the article's Creative Commons licence, unless indicated otherwise in a credit line to the material. If material is not included in the article's Creative Commons licence and your intended use is not permitted by statutory regulation or exceeds the permitted use, you will need to obtain permission directly from the copyright holder. To view a copy of this licence, visit http://creativecommons.org/licenses/by/4.0/.

\section{References}

Collins, H. (1974). The TEA set: Tacit knowledge and scientific networks. Science Studies, 4(2), 165-186.

Collins, H. (1996). Embedded or embodied: Hubert Dreyfus's what computers still Can't do. Artificial Intelligence, 80(1), 99-117.

Collins, H. (2000). Four kinds of knowledge, two (or maybe three) kinds of embodiment, and the question of artificial intelligence. In J. Malpas \& M. A. Wrathall (Eds.), Heidegger, coping, and cognitive science: Essays in honor of Hubert L. Dreyfus (Vol. 2, pp. 179-195). Cambridge: MIT Press.

Collins, H. (2004a). Interactional expertise as a third kind of knowledge. Phenomenology and the Cognitive Sciences, 3(2), 125-143.

Collins, H. (2004b). The trouble with Madeleine. Phenomenology and the Cognitive Sciences, 3(2), 165-170.

Collins, H. (2008). Response to Selinger on Dreyfus. Phenomenology and the Cognitive Sciences, 7, 309-311.

Collins, H. (2010). Tacit and explicit knowledge. Chicago: University of Chicago Press.

Collins, H. (2011). Language and Practice. Social Studies of Science, 41(2), 271-300. https://doi.org/10.1177 $/ 0306312711399665$.

Collins, H. (2012). Language as a repository of tacit knowledge. In T. Schilhab, F. Stjernfelt, \& T. Deacon (Eds.), The symbolic species evolved (pp. 235-239). Dordrecht: Springer. https://doi.org/10.1007/978-94007-2336-8_11.

Collins, H. (2013). Three dimensions of expertise. Phenomenology and the Cognitive Sciences, 12(2), 253273. https://doi.org/10.1007/s11097-011-9203-5.

Collins, H. (2017a). Interactional expertise and embodiment. In J. Sandberg, L. Rouleau, A. Langley, \& H. Tsoukas (Eds.), Skilful performance: Enacting expertise, competence, and capabilities in organizations: Perspectives on Process Organization Studies (P-PROS) (Vol. 7, pp. 125-146). Oxford: Oxford University Press.

Collins, H. (2017b). Gravity's kiss: The detection of gravitational waves. Cambridge: MIT Press.

Collins, H. (2018). Artifictional intelligence: Against Humanity's surrender to computers. Cambridge: Polity Press.

Collins, H. (2019a). Remembering Bert Dreyfus. AI and Society Special issue, 32(2), 373-376.

Collins, H. (2019b). Forms of life: The method and meaning of sociology. Cambridge: MIT Press.

Collins, H., \& Evans R. (2007). Rethinking Expertise. Chicago: University of Chicago Press.

Collins, H., \& Evans, R. (2015). Expertise Revisited I - Interactional expertise. Studies in History and Philosophy of Science, 54, 113-123. A pre-print is available at http://arxiv.org/abs/1611.04423.

Collins, H., \& Sanders, G. (2007). They give you the keys and say "drive it:" managers, referred expertise, and other expertises in Collins (ed) Case Studies of Expertise and Experience: special issue of Studies in History and Philosophy of Science, 38, 4, 621-641 [December].

Collins, H., Evans, R., \& Weinel, M. (2016). Expertise revisited II - Contributory expertise. Studies in History and Philosophy of Science, 56, 103-111.

Collins, H., Evans, R., Innes, M., Kennedy, E., Mason-Wilkes, W., \& McLevey, J. (under submission). Faceto-face: Communication and the liquidity of knowledge.

Dreyfus, H. (1967). Why computers must have bodies in order to be intelligent. Review of Metaphysics, 21(1), 13-32.

Dreyfus, H. (1972). What computers can't do. Cambridge: MIT Press. 
Dreyfus, H. (2017). Embodied expertise according to Martin Heidegger, Maurice Merleau-Ponty, and Samuel Todes. In J. Sandberg, L. Rouleau, A. Langley, \& H. Tsoukas (Eds.), Skilful performance: Enacting expertise, competence, and capabilities in organizations: Perspectives on Process Organization Studies (P-PROS) (Vol. 7, pp. 147-159). Oxford: Oxford University Press.

Du Bois, W. E. B. (1994). The souls of black folk. Avenel: Gramercy Books.

Gier, N. (1981). Wittgenstein and Heidegger : A phenomenology of forms of life. Tijdschrift Voor Filosofie, 43(2), 269-305.

Giles, J. (2006). Sociologist fools physics judges. Nature 442:8.

Jackson, F. (1982). Epiphenominal qualia. The Philosophical Quarterly, 32(127), 127-136.

Kuhn, T. S. (1962). The structure of scientific revolutions. Chicago: University of Chicago Press.

Malpas, J., \& Wrathall, M. A. (eds.) (2000). Heidegger, coping, and cognitive science: Essays in honor of Hubert L. Dreyfus. Cambridge, Massachusetts: MIT Press.

Munson, T. (1962). Wittgenstein's phenomenology. Philosophy and Phenomenological Research, 23(1), 3750. https://doi.org/10.2307/2104987.

Sacks, O. (1985). (the man) who mistook his wife for a hat. London: Duckworth.

Selinger, E. (2003). The necessity of embodiment: The Dreyfus-Collins debate. Philosophy Today, 47(3), 266-279.

Selinger, E. (2008). Collins's incorrect depiction of Dreyfus's critique of artificial intelligence. Phenomenology and the Cognitive Sciences, 7, 301-308.

Selinger, E., Dreyfus, H., \& Collins, H. (2007). Embodiment and interactional expertise. In Collins (ed.), Case Studies of Expertise and Experience: Special Issue of Studies in History and Philosophy of Science, 38(4): $722-740$.

Todes, S. (2001). Body and world. Cambridge: MIT Press.

Publisher's note Springer Nature remains neutral with regard to jurisdictional claims in published maps and institutional affiliations. 